\title{
ESTRECHANDO VINCULOS ENTRE "COMUNIDADES" EN TORNO AL PATRIMONIO ARQUEOLÓGICO. LAS PRÁCTICAS EXTENSIONISTAS DESDE UN PROGRAMA DE ARQUEOLOGIA PÚBLICA
}

\section{A U T O R A S}

\section{Mariela E. Zabala}

marielaeleonora@gmail.com

\section{Mariana Fabra}

vivianemcc@gmail.com
CONICET, Programa de Arqueología Pública, (SEU, FFyH, Museo de Antropología, UNC).

\section{R E S U M E N}

1 Programa dependiente de la Secretaría de Extensión Universitaria y del Museo de Antropología (Facultad de Filosofía y Humanidades, Universidad Nacional de Córdoba).
Secyt, Programa de Arqueología Pública (SEU, FFyH, Museo de Antropología, UNC).
Cada día hay mayor conocimiento, apropiación, reinvención y ejercicio de los derechos culturales por parte de agentes sociales pertenecientes a distintas comunidades: locales, académicas y originarias. En la provincia de Córdoba (Argentina), estos derechos se manifiestan en demandas y reclamos por la recuperación de bienes arqueológicos en riesgo, que consideran parte de su patrimonio cultural, en la organización y participación de encuentros, jornadas y charlas sobre historia, memoria e identidad, y en la búsqueda por estrechar vínculos con la Universidad Nacional de Córdoba para conocer más sobre los pueblos originarios del actual territorio cordobés. Esta nueva realidad socio-cultural-escolar ha requerido al Programa de Arqueología Pública ${ }^{1}$ (PAP) repensar, después de 12 años de trabajo, sus prácticas extensionistas con las comunidades donde se llevan a cabo tareas de rescate arqueológico. El presente trabajo busca dar a conocer la problemática abordada desde el PAP, en su objetivo de estrechar vínculos con las comunidades a partir de prácticas extensionistas concretas, en pos de la recuperación, investigación, conservación preventiva, valoración y educación de los bienes que las mismas consideran de valor patrimonial.

Palabras claves: Patrimonio Arqueológico, Arqueología Pública, Córdoba (Argentina).

Todos os dias há mais conhecimento, apropriação, reinvenção e exercício dos direitos culturais por agentes sociais pertencentes a diferentes comunidades: local, acadêmico e nativas. Na província de Córdoba (Argentina), esses direitos são manifestados em demandas e reivindicações de recuperação arqueológica em risco, consideram parte do seu património cultural e participação na organização de reuniões, seminários e palestras sobre memória, história e identidade, e da busca de laços mais estreitos com a Universidad Nacional de Córdoba para aprender mais sobre os povos nativos do atual território de Córdoba. Esta nova realidade sócio-cultural-escolar tem exigido do Programa de Arqueologia Pública (PAP) repensar, após 12 anos de práticas de trabalho, de extensão com as comunidades onde eles realizam salvamento arqueológico. Este trabalho busca a conscientização das questões em jogo a partir do PAP, no 
seu objectivo de reforçar os laços com as comunidades de práticas específicos de extensão, após a recuperação, pesquisa, conservação preventiva, educação e avaliação dos bens que considerada patrimônio.

Palavras-chave: Patrimônio Arqueológico, Arqueologia Pública, Córdoba (Argentina).

\section{A B S T R A C T}

Today, there is more knowledge, appropriation, reinvention and exercise of Cultural Rights by social agents belonging to different communities: local, academic and native. In Córdoba (Argentina), these rights are manifested in a) demands and claims of archaeological remains being at risk, remains that communities consider part of their cultural heritage, b) participation in the organization of meetings, seminars and lectures about history, memory and identity, and in c) search for closer ties with the Universidad Nacional de Córdoba to learn more about the native peoples that inhabited Córdoba in the past. This situation has required to the Programa de Arqueología Pública (PAP) rethink, after 12 years of work, extension practices with the communities where they conduct archaeological rescues. The aim of this paper is to release the problems addressed by PAP, in its aim to strengthen links with communities from specific extension practices, after recovery, research, preventive conservation, education and assessment about archaeological remains considerer heritage.

Keywords: Archeological Heritage, Public Archeology, Córdoba (Argentina).

I N T R O D U Ç Ã O
Desde un punto de vista geográfico, la provincia de Córdoba ocupa parte de la región austral de las Sierras Pampeanas, abarcando los cordones montañosos de las provincias de Córdoba y San Luis, así como las llanuras orientales y occidentales aledañas (CAPITANELLI, 1979). Su posición geográfica intermedia, ocupando el centro del territorio argentino, fue significativa a lo largo del tiempo en la historia de las poblaciones que la habitaron. El registro arqueológico da cuenta de una ocupación humana de por lo menos 12000 años AP (FABRA, 2009). Por lo cual es muy frecuente el hallazgo de sitios arqueológicos cuando se realizan cualquier tipo de obras de infraestructura, así como debido por la acción de agentes naturales, tales como crecidas de ríos o por grandes torrentes de agua ocasionados por lluvias estivales, erosión hídrica de costas de lagunas, etc. Estas causas ponen al descubierto sitios de gran valor para conocer el modo de vida de los antiguos pobladores de esta región.

Desde el último cuarto del siglo XIX, esta región fue de gran interés para el estudio de naturalistas y arqueólogos, interesados en el conocimiento de la flora, la fauna así como la historia de los antiguos pobladores. El impulso a estas investigaciones fue dado de un modo especial por la creación de la Facultad de Ciencias Físico-Matemáticas (hoy Facultad de Ciencias Exactas, Físicas y Naturales) de la Universidad Nacional de Córdoba (1876) y la Academia Nacional de Ciencias (1878). En la creación y puesta en marcha de estos espacios académicos- universitarios se invitó a destacados naturalistas alemanes de la época, así como a científicos argentinos (TOGNETTI, 2000). 
2 Entre 1999 y 2007 nuestro grupo se denominó "Equipo de Arqueología de Rescate y educación patrimonial" (Museo de Antropología, FFyH, UNC), luego "Proyecto de Arqueología Publica" (20772011, Museo de Antropología, $\mathrm{FFyH}$, UNC) y "Programa de Arqueología Publica" (2011 y continua, Museo de Antropología y SEU-FFyH, UNC).
Los primeros argentinos interesados en el pasado humano de la región, desde fines del siglo XIX hasta mediados del siglo $X X$, fueron Florentino Ameghino (1885-1889), Alfredo Castellanos, Félix Outes (1878-1939), Francisco De Aparicio (1892-1851), Monseñor Pablo Cabrera (1857-1936), Antonio Serrano (1899-1982), Aníbal Montes (1886-1859) y Alberto Rex González (1918-2012) (LAGUENS y BONNIN, 2010; ZABALA, 2010a). Algunos de los aportes que nos interesa retomar a los fines del presente artículo son sus contribuciones a la interpretación de la construcción histórica del pasado cordobés: el aporte de Ameghino al establecer una cronología relativa de dos etapas en el desarrollo cultural, una inicial de cazadores y otra posterior de agricultores; de Outes, quién utilizó la técnica de mapas de distribución de rasgos para delimitar las áreas culturales en el espacio geográfico y analizar los cambios culturales a partir de la difusión. Para hacer sus estudios acudió a las crónicas de viajeros de la época de la conquista española y comenzó a hablar de "Comechingones" para denominar a los antiguos pobladores del territorio cordobés (LAGUENS Y BONNIN, 2010). Este modo de historizar y comprender el pasado, así como de nombrar a los antiguo pobladores, fue retomado en los trabajos de Cabrera, De Aparicio y Montes, y se profundizaron y sistematizaron en la obra Los Comechingones de Serrano (1945). Esta obra cristaliza un pasado de los indígenas, homogeneizando su modo de vida, quitándole profundidad y complejidad histórica. Hasta hoy, este libro es muy consultado y utilizado como material de referencia para producir conocimiento y enseñar sobre los indígenas de Córdoba así como para producir memorias sociales indígenas presentes.

En este hito histórico académico se funda la importancia de nuestro Programa, el cual intenta discutir y poner en tensión estos temas, tanto en la sociedad como en el mundo académico universitario, vinculados al poblamiento originario de la provincia, los modos de vida de sus poblaciones a lo largo del Holoceno, a partir de las investigaciones realizadas sobre más de 80 sitios y restos arqueológicos recuperados a lo largo de 12 años de trabajo en la provincia de Córdoba ${ }^{2}$ (FABRA et al., 2008a, 2008b; FABRA y DEMARCHI, 2009; FABRA et al. 2012; ZABALA et al., 2012). En este artículo queremos sistematizar, reflexionar y dar a conocer la problemática abordada desde el PAP, con el objetivo de estrechar vínculos con las comunidades a partir de prácticas extensionistas, en pos de la recuperación, investigación, conservación preventiva, valoración y educación de los bienes que las mismas consideran de valor. Buscamos reconfigurar los vínculos entre las comunidades locales, los pueblos originarios y los universitarios en torno al patrimonio arqueológico, generando espacios de encuentros multivocales donde poner en tensión los saberes ancestrales, los discursos políticos y los saberes académicos.

\section{Ayer Arqueología de rescate y educación patrimonial... Hoy Arqueología Pública: los desafíos de la multivocalidad}

El surgimiento de la Arqueología Publica puede vincularse con las transformaciones sociales y académicas que se han desarrollado en las últimas décadas a nivel global, así como con el surgimiento de posicionamientos 
críticos hacia la neutralidad de la ciencia y la objetividad, heredadas del positivismo (FUNARI y ROBRAHN-GONZÁLEZ, 2006). La Arqueología de Rescate surgió a partir de los debates que se generaron, principalmente en Estados Unidos entre las décadas de 1960 y 1970 por el problema de la pérdida irreparable de sitios arqueológicos y paleontológicos con motivo de la construcción de grandes obras de infraestructura que producían enormes remociones de tierra o dejaban bajo agua vastas porciones de territorio. Así, el objetivo de esta disciplina era registrar y recuperar la mayor cantidad bienes y sitios arqueológicos en peligro de destrucción. Esta práctica generó un gran debate en Estados Unidos acerca de los criterios de selección de los bienes patrimoniales a preservar, al respecto R. Thompson (1982) considera que todo hallazgo tiene significado por su posible contribución al conocimiento del pasado y por ende debe ser salvado. Por lo tanto los bienes rescatados tienen un significado actual, entienda sé al momento del rescate, y uno potencial a medida que se generen nuevos conocimientos en el desarrollo científico (ENDERE, 2000). Con el mismo sentido, pero mayor especificidad, nació la Arqueología Pública en ese mismo país, en el año 1972, tras la publicación del libro Public Archaeology de Carles McGimsey, donde es acuñado por primera vez el término. En él, presenta las acciones de publicidad que se hacían desde los parques nacionales y pone de relieve la integración de las comunidades locales con el patrimonio. Años más tarde, en 1999, el European Journal of Archaeology publica dos volúmenes dedicados a la Arqueología Pública, pero en la introducción, el museólogo inglés Tim Schadla-Hall, habla de la Arqueología Comunitaria. La diferencia se centra en que Europa no tenía como problema la relación de los indígenas con el patrimonio como referente de la identidad y la territorialidad, como si ocurría en Estados Unidos Hay dos ideas básicas comunes que la definen como son la teoría y la acción (ALMANSA SANCHEZ, 2011).

En esta relación entre la práctica arqueológica, el patrimonio y la comunidad es que surge la Arqueología Pública, donde el arqueólogo toma una posición políticamente activa. La interacción con las comunidades (locales, nacionales, trasnacionales) pasa a tener un papel fundamental tanto en la práctica como en la teoría arqueológica (FUNARI y ROBRHAN-GONZÁLEZ, 2007). Esta sub disciplina de la Arqueología reúne una larga lista de temas como son el saqueo y tráfico de bienes culturales; la relación entre arqueología y nacionalismo; derechos humanos; el reconocimiento de los derechos de los grupos indígenas a sus patrimonios culturales, la representaciones de la arqueología en los medios de comunicación; la industria del patrimonio y la autenticidad de las representaciones del pasado; y la relación entre patrimonio y educación entre otros temas posibles (CONFORTI, 2009). En los últimos años, ha quedado de manifiesto la importancia de entender a la práctica arqueológica como un saber compartido, entre investigadores y comunidades involucradas en la protección de su patrimonio, no sólo como la producción de conocimientos acerca del pasado, sino con un grado de compromiso social hacia el presente, por parte de los investigadores (CASTRO et al., 2007).

Con este marco de referencia, reflexionemos acerca de la particularidad de las prácticas realizadas en Arqueología Pública, en Argentina, puntualmente el desarrollo que las mismas han tenido en Córdoba en los últimos años 
3 Sobre el tema, ver Informes de Gestión del Museo de Antropología FFyH-UNC.
4 El Reglamento del Museo de Antropología aprobado por Ordenanza 1/2002 del Honorable Consejo Directivo de la FFyH-UNC, con fecha del 16/09/2002, reconoce las siguientes áreas: Investigación, Educación y Difusión, Conservación, Documentación y Museografía. porque, como señala Gnecco (2007), no existe una única manera de hacer Arqueología Pública.

Desde fines de la década de 1990, el Museo de Antropología de la Facultad de Filosofía y Humanidades, Universidad Nacional de Córdoba fue receptor de innumerables pedidos por parte de diversos agentes sociales, instituciones estatales (museos, escuelas, municipios) y organizaciones no gubernamentales (Amigos de la Arqueología, aficionados a la arqueología, asociaciones patrimoniales) para dar respuesta frente a situaciones de pérdida o destrucción de sitios arqueológicos en la provincia de Córdoba (FABRA et al., 2005, 2008a, 2008b). Estas demandas llevaron a la directora del Museo, Mgter. Mirta Bonnin a procurar las políticas universitarias pertinentes para formar recursos humanos idóneos, así como institucionalizar equipos de trabajo interdisciplinarios con el fin de transformar a la institución en un espacio de referencia para la sociedad cordobesa sobre la recuperación y puesta en valor de los patrimonios ${ }^{3}$.

Fue así como se formaron dos equipos, uno que llevaría adelante tareas vinculadas a la práctica de la arqueología de rescate, a la investigación de las colecciones y los sitios arqueológicos en riesgo, y otro orientado a la realización de prácticas de educación patrimonial, en ambos equipos, priorizando la formación de recursos humanos del grado. Por un lado difundían y comunicaban los resultados de los trabajos y las investigaciones académicas realizadas sobre estos sitios, y por otro generara debate y problematizara acerca de temas patrimoniales, el rol del arqueólogo y los procesos de patrimonialización, a través de la sensibilización de los pobladores mediante prácticas de educación e interpretación patrimonial (ZABALA et al. 2006, 2008, $2010 b$ y $2010 c$ ).

En el año 2006, se ganó un subsidio de la Secretaría de Políticas Universitarias del Ministerio de Educación de la Nación, con un proyecto de investigación y extensión dirigido por el Dr. Andrés Laguens y Bonnin. Dicho proyecto preveía el trabajo conjunto de arqueólogos y educadores interesados en los problemas del patrimonio arqueológico, y fue la base del presente Programa de Extensión. Por las particularidades de sus objetivos y metodologías de trabajo no podía ser ubicado en una única Área ${ }^{4}$ del Museo, ya que a la vez contemplaba la realización de trabajos de investigación, conservación de colecciones y educación, desde un enfoque multidisciplinario.

En ese momento, el proyecto se redactó en torno a una propuesta de una estudiante de la Carrera de Historia, oriunda de la localidad de Villa de Soto cercana a Charquina, quien manifestó su preocupación por la pérdida de aleros con arte rupestre por la explotación minera (URIBE y OCHOA, 2008). Parte de los resultados de las investigaciones realizadas en el marco de dicho proyecto se publicaron en Arqueoweb. Revista de Arqueología en Internet (2008, número 10), y en Educar en Patrimonio: Educar en Valores. Propuesta didáctica para interpretar el patrimonio en el aula (2006), publicación del Museo destinada a docentes como estudiantes del nivel primario. Esta última publicación surgió a partir de nuestra inquietud de que los conocimientos generados en el equipo llegaran, con la transposición educativa pertinente, al mayor número de personas posibles, teniendo en cuenta la diversidad y potenciándola como riqueza para abordar los problemas planteados. El deseo 
es que estos saberes tengan un impacto inmediato, en este caso, en el sistema educativo provincial.

En años recientes seguimos trabajando de la provincia de Córdoba, y en nuevas publicaciones que dieran cuenta del trabajo y las inquietudes del equipo. Nuestro último cuadernillo, titulado Pueblos de las sierras, del piedemonte, de los valles y la llanura: la protección del patrimonio arqueológico de las sociedades indígenas de Córdoba (2010), se pensó para aquellos educadores que quisieran abordar el estudio de los modos de vida de los pueblos originarios que habitaron las sierras, el piedemonte, los valles y la llanura de Córdoba desde su patrimonio material. Lo novedoso de la propuesta es que aporta una nueva mirada sobre estas sociedades a partir de investigaciones arqueológicas recientes, haciendo hincapié en la antigüedad de los pobladores de Córdoba y la diversidad en los modos de vida desarrollados en estos 10.000 años, así como de los estudios de la arqueología pública realizados en la provincia desde nuestro proyecto.

En el año 2011 formalizamos el Programa de Arqueología Pública: patrimonio arqueológico y derechos culturales en el Noreste de la provincia de Córdoba, como resultado de la interacción entre el Museo de Antropología (FFyH, UNC), la Secretaría de Extensión Universitaria (FFyH-UNC) y distintos museos del este de la provincia. Delimitamos el trabajo a esta región geográfica no sólo por los numerosos e importantes sitios arqueológicos identificados en la margen sur de la Laguna Mar Chiquita, expuestos principalmente debido a la acción erosiva de las aguas y las fluctuaciones que ha tenido su nivel en los últimos años, sino también por los vínculos establecidos con sus pobladores y sus museos, que muestran un gran interés por conservar estos sitios, así como conocer y difundir su historia. Este interés también se fundamente en que los Bañados del Río Dulce y la Laguna Mar Chiquita ha sido declarada Reserva Provincial de Usos Múltiples (1994), sitio Ramsar (2002) y sitio de importancia continental para aves playeras (2008).

Esta región atraviesa diferentes problemáticas que ponen en riesgo sitios arqueológicos y el ambiente. Esta situación, sumada a la ausencia de políticas estatales en torno a su protección generó que en el transcurso de 2012 se hayan realizado una serie de reuniones, organizadas por museos de la región, asociaciones civiles y nuestro Programa, con el objetivo de establecer acciones y estrategias para cambiar la situación. En estas reuniones han participado representantes de estas organizaciones, vecinos de las distintas comunidades y autoridades municipales, a las cuales se les ha planteado la gravedad de la situación y las posibles acciones que pueden pensarse para revertir la misma a través de distintas propuestas: elaboración de cartas de riesgo arqueológico, que posibiliten un plan de manejo de la región, ofrecer charlas y talleres, que permitan problematizar este tema e involucrar a los vecinos en cuestiones vinculadas a la protección del patrimonio arqueológico y designar a la región como Reserva Arqueológica.

Si bien quienes nos convocan ante la aparición de restos arqueológicos son los museos municipales de la región, es notable que las distintas comunidades reconstruyan su historia principalmente a partir de un hito como fue la llegada del ferrocarril a fines del siglo XIX. Aunque no desconocen la existencia de restos arqueológicos que dan cuenta de una compleja y profunda historia para las comunidades originarias de la región que se remonta como 
5 Se realizaron fechados radiocarbónicos sobre restos óseos humanos arqueológicos de diversos sitios de la costa sur de la laguna Mar Chiquita, siendo el más antiguo de C14 $4525 \pm 20$ años AP (FABRA y DEMARCHI, 2009). mínimo a 5000 años $^{5}$, en el imaginario local los pobladores se reconocen como hijos de inmigrantes europeos, en su mayoría italianos y españoles, aunque también hay descendientes de europeos del Este. Estas identidades construidas en torno a un origen como localidades vinculados a la inmigración reciente europea, se contraponen con una serie de estudios basados en ADN mitocondrial de pobladores actuales de las localidades de La Para, Miramar y La Tordilla, ambas ubicadas en el noreste de la provincia de Córdoba, los cuales han demostrado que el $80 \%$ de las personas analizadas presenta alguno de los 4 linajes maternos amerindios (GARCÍA y DEMARCHI, 2009). Aunque reconocemos que la identidad se construye desde distintas dimensiones sociales, no podemos negar que una de esas dimensiones es la filiación por el ADN.

Además de los museos regionales, a partir de 2011 nuevos actores se han sumado a este diálogo en torno al patrimonio arqueológico, y son las comunidades Comechingonas de la provincia de Córdoba. A partir de la conmemoración de los 500 años de la llegada de los españoles a América, comenzó un proceso de autoreconocimiento de los Pueblos Comechingones de Córdoba, que ha ido tomando fuerza y consolidándose en los últimos años, culminando con el reconocimiento por parte del Instituto Nacional de Asuntos Indígenas de nueve de estas comunidades. Sus intereses, nivel de involucramiento y participación en trabajos de campo nos desafían a entablar nuevos diálogos en torno a éticas de trabajo, el uso y valor de los bienes arqueológicos, intercambiar conocimientos en torno a los pueblos originarios de Córdoba, así como discutir protocolos de trabajo.

El proceso descripto anteriormente no sólo da cuenta de cómo fue construyéndose nuestro equipo en estos 12 años en la práctica de la Arqueología Pública en Córdoba, desde un ámbito académico universitario, sino de la particularidad de esta práctica en nuestra provincia, en un escenario que ha ido complejizándose en el tiempo, gracias a la participación y los intereses de nuevos actores. Entonces, ya no sólo entramos en diálogo con vecinos, miembros del estado, ciudadanos movilizados por intereses culturales- patrimoniales o estudiantes oriundos de localidad con sitios arqueológicos sino también con miembros de los pueblos originarios.

Reconocemos que como antropólogos, biólogos, historiadores, geógrafos y arqueólogos producimos un tipo particular de conocimientos y saberes sobre el pasado. A partir de nuestras prácticas extensionistas intentamos acercar y devolver estos saberes a las comunidades interesadas en conocer más acerca de las poblaciones que habitaron este territorio en el pasado, discutir acerca de la complejidad y riqueza de sus modos de vida a lo largo del tiempo. Aportar desde un tipo particular de saberes, construidos desde la práctica arqueológica y antropológica, a los procesos de construcción de identidades y memorias locales. Consideramos que la realización de estas tareas desde un Museo Universitario, entendido como nexo entre el conocimiento sobre el patrimonio y la sociedad, es un aspecto expresivo de la democratización y extensión de la cultura y la ciencia, y un importante elemento a tener en cuenta en los procesos de inclusión social y cultural. 


\section{Prácticas extensionistas}

Consideramos que las comunidades tienen el derecho de conocer acerca de los resultados de los trabajos que arqueólogos y antropólogos realicen sobre bienes arqueológicos que las mismas consideran de valor patrimonial, puntualmente, conocer acerca de los modos de vida de los pobladores que habitaron el territorio que hoy ocupan esas comunidades, así como decidir sobre su gestión. Desde nuestro programa apoyamos las gestiones que puedan realizar estas comunidades y organizaciones públicas sobre sus bienes arqueológicos. En el caso que en estas comunidades haya museos públicos, iniciamos las gestiones frente a la Dirección de Patrimonio Cultural del Gobierno de la Provincia de Córdoba para que estos bienes formen parte de las colecciones de dichos museos. De este modo generamos prácticas de intervención social donde aportamos a la resolución de problemáticas vinculadas al patrimonio arqueológico, y esa participación nos compromete a repensar, como académicos, nuestras propias investigaciones con un claro tamiz social. Valoramos al conocimientos como un bien público que nos pertenece a todos (PACHECO, 2008).

Entendemos a la Educación Patrimonial como la didáctica y la interpretación de los bienes patrimoniales. De esta forma, en los espacios que generamos y proponemos desde nuestro programa nos impulsa el deseo de construir experiencias de interacción cooperativa, donde los participantes locales sean protagonistas del proceso y de la toma de decisiones. Estos espacios suelen generan situaciones de tensión o disenso al interior de la comunidad o entre los participantes de las actividades, en torno a la apropiación y significación del patrimonio, así como también agradecimiento y respeto por la construcción del pasado local que realizamos desde estas prácticas. A continuación reseñamos las principales actividades extensionistas realizadas desde nuestra constitución como Programa de Arqueología Pública.

\section{Trabajos de Arqueología de Rescate}

Los trabajos de rescate fueron convocados por museos y municipios del interior provincial, como por denuncias realizadas por particulares ante instituciones judiciales (Juzgados, Fiscalías) o policiales (comisarias). Esto es así porque gran parte de los hallazgos tienen que ver con la aparición de restos óseos humanos. Desde el año 2009 se ha puesto en marcha un Convenio entre el Poder Judicial de la provincia de Córdoba, el Equipo Argentino de Antropología Forense y nuestro programa, dentro del Museo de Antropología (FFyH, UNC) para dar respuesta ante este tipo de pedidos. Mediante ese convenio, inédito en la Argentina, antropólogos forenses y arqueólogos realizan la exhumación en conjunto de los restos en el campo, y determinan si se trata de restos humanos, en primer término, y si son de interés forense o arqueológico. Una vez estimado su carácter, se deriva los hallazgos al Instituto de Medicina Forense, Museo de Antropología - FFyH, UNC - o museos públicos de las localidades donde se han realizado los hallazgos (Figura 1a).

En este marco, se han realizado un total de 14 rescates casos arqueológicos (10 en 2011 y 4 en lo que va del 2012). Por otro lado, se trabajó en un total de 36 casos de interés forense ( 23 en 2011 y 13 en 2012). En estos traba- 
6 Si bien la Universidad Nacional de se encuentra próxima a cumplir 400 años de historia, ciertas disciplinas son de reciente desarrollo en esta casa de estudios. Tal es el caso de la Antropología: en el año 2002 se creó la Maestría en Antropología, en el año 2009 el Doctorado en Ciencias Antropológicas y en el año 2010 la Licenciatura en Antropología. Esta reconstrucción histórica de la institucionalización académica de la Antropología en la UNC permite dar cuenta de la importancia que tiene para este Programa de Extensión incorporar estudiantes de dicha carrera a modo de espacio formador no solo de la disciplina sino de las prácticas extensionistas. jos participaron alumnos de grado de la carrera Licenciatura en Antropología 6 (FFyH-UNC), tanto en los trabajos de campo como en el posterior análisis bioantropológico de los restos. Para realizar está tareas, los estudiantes deben firmar una Protocolo de Trabajo donde se les informa acerca de las normas de trabajo tanto en el campo como en el laboratorio. Consideramos que este instrumento ayuda a generar compromiso y sentido de pertenencia con el Programa, así como una actitud ética en el trabajo con bienes arqueológicos patrimoniales.

Durante las tareas de rescate los pobladores, miembros de los pueblos originarios así como turistas se acercan para preguntar qué tareas se están realizando, quienes somos, cómo trabajamos (Figura 1b). Para responder algunas de estas inquietudes hemos producido un díptico que se reparte durante el trabajo de campo. El mismo está estructurado a partir de un estudio previo donde registramos cuáles eran las preguntas más frecuentes, así como información acerca de normas de comportamiento esperadas para la realización del trabajo: ¿Quiénes estamos trabajando? ¿Qué es la Arqueología Pública?¿Qué actividades realizamos?¿Por qué es importante que trabajen arqueólogos y antropólogos? ¿Por qué es importante la participación de la comunidad en las charlas y talleres? ¿Querés conocer más? Con este material buscamos entablar un vínculo de confianza, reconocimiento y respecto con los visitantes. Este material comenzó a ser entregado en el mes de Julio del corriente año, por lo cual aún no tenemos una evaluación de los resultados.

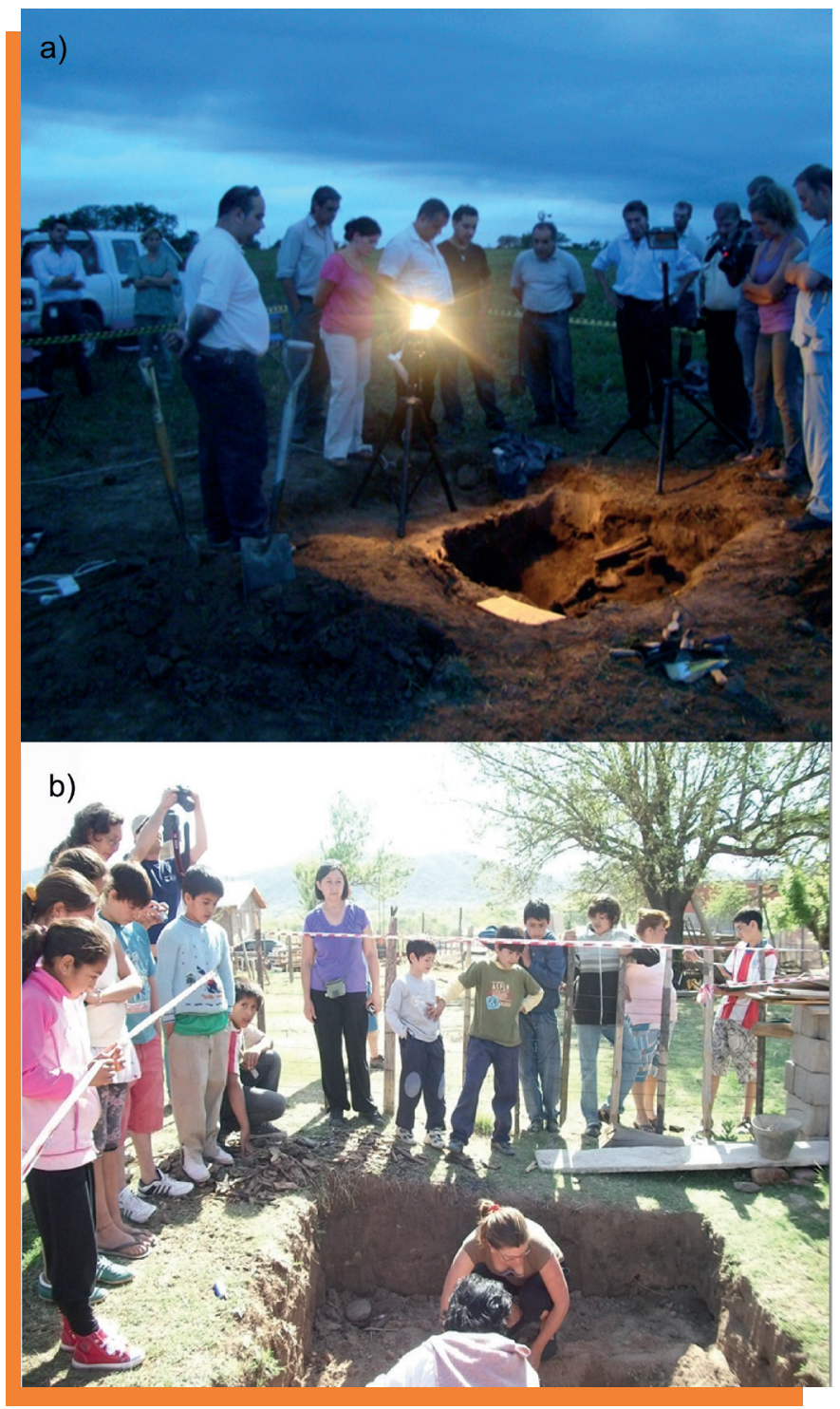

Figura 1. Trabajos de Arqueología de rescate en la provincia de Córdoba. 1a: sitio Tio Pujio 01 (2010), $1 \boldsymbol{b}$ : sitio Loteo 5 (2011). 
Asimismo, cabe destacar que dentro de las actividades realizadas desde el Programa contemplamos el análisis y acondicionamiento de colecciones, el relevamiento e inventario de colecciones arqueológicas - principalmente bioantropológicas - de otros museos del interior provincial, a partir de la solicitud de dicho servicio.

\section{Restitución de restos humanos}

A partir del pedido realizado por la Intendencia de la localidad de Villa de Tránsito, se procedió a la restitución de restos óseos humanos recuperados en el sitio arqueológico "Arenera Pintussi-Tránsito" de la mencionada localidad, junto con una copia del informe realizado a partir del análisis del material. La devolución tuvo lugar en el marco los festejos por el Día de los Orígenes, el 14 de Marzo de 2011, y el hallazgo fue declarado de interés municipal (Figura 2a). Durante el mismo acto, se dictó una conferencia destinada al público en general, en donde se describió el Convenio mediante el cual se procedió a la recuperación de los restos, así como los Protocolos de Trabajo en arqueología, tanto en campo como en laboratorio, los resultados obtenidos a partir del análisis de los restos óseos recuperados, y una síntesis general acerca del modo de vida de los habitantes prehispánicos de la zona, a partir de investigaciones previas en cuanto a antigüedad de los restos, alimentación, actividades cotidianas y prácticas mortuorias. Por último se abordaron conceptos como patrimonio arqueológico, educación patrimonial y pluriculturalidad, entre otros (ACHINO et al., 2012).
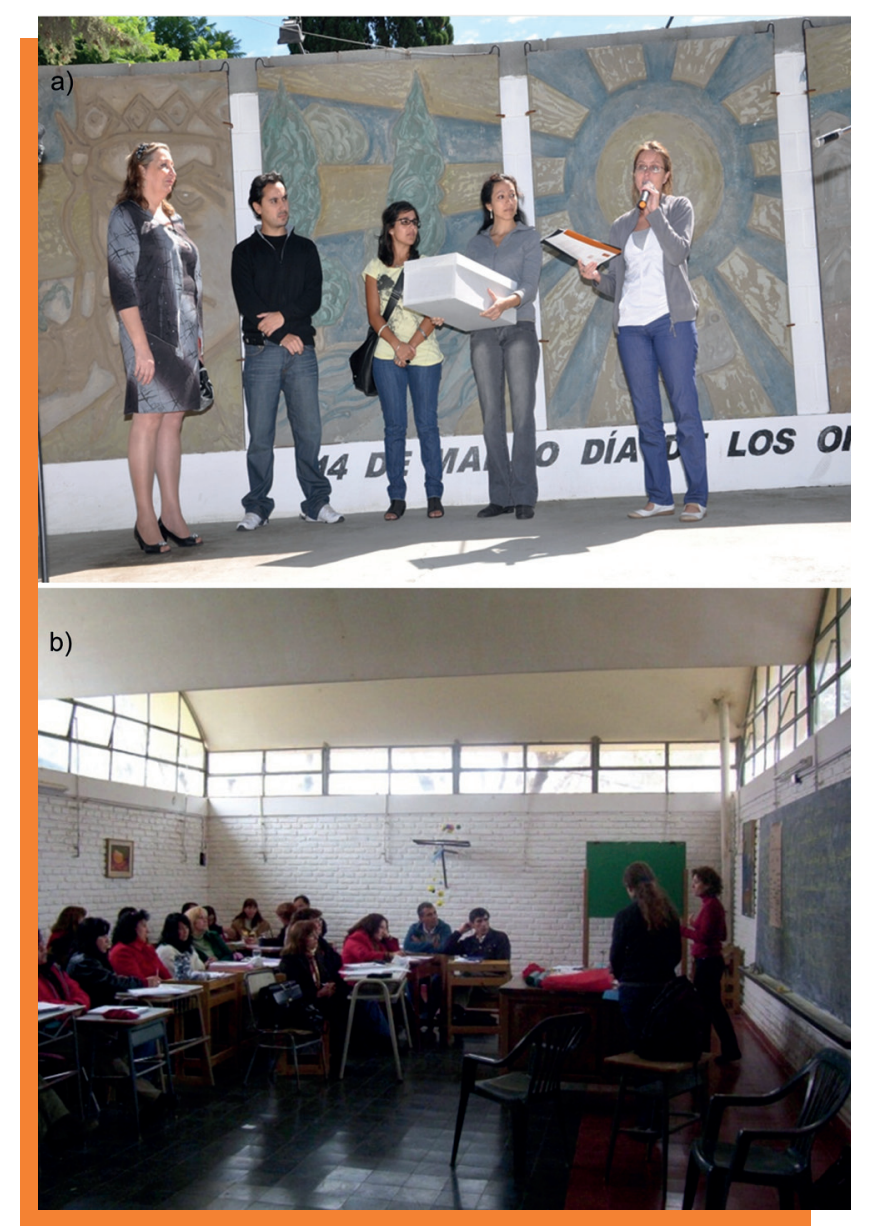

Figura 2. Actividades extensionistas. 2a: restitución de restos en Villa de Tránsito (2010); $\mathbf{2} \boldsymbol{b}$ : Dictado de charla en San Carlos Minas. 


\section{Charlas y talleres}

Las charlas y talleres, orientados a distintos públicos, son parte de los trabajos de arqueología realizados en las distintas localidades donde se produjeron hallazgos. En estas actividades, cuya modalidad es de charla-taller, no solamente se dan a conocer los resultados de las investigaciones realizadas en la zona para que las comunidades interesadas conozcan más sobre los modos de vida de las sociedades prehispánicas que habitaron Córdoba, sino que también se realizan actividades donde los habitantes de la comunidad participan activamente como agentes constructores de su patrimonio (Figura 2b).

En 2010 se dictaron dos charlas, acerca de los precursores de las ciencias antropológicas en Córdoba, y sobre los pueblos originarios que habitaron la provincia, a alumnos de profesorados de la ciudad de Córdoba. Asimismo, se diseñaron y planificaron charlas de difusión sobre los aportes que pueden hacer a la comunidad las investigaciones arqueológicas para conocer su pasado, y en base a esos nuevos saberes, aportar a la reconstrucción de su historia e identidad. Las mismas tienen por objetivo sensibilizar a la comunidad con respecto a la importancia del trabajo de los arqueólogos en caso de hallazgo fortuito así como en excavaciones programadas. Por otro lado, buscamos que la comunidad conozca sus derechos culturales, se apropie de ellos y los haga cumplir. Las charlas están estructuras en un exposición por miembros del equipo, luego una trabajo en grupo de los participantes a partir de la exposición y un cierre grupal. La metodología de la charla es aula-taller como estrategia de enseñanza donde el educador y el participante tienen un rol activo en el aprendizaje (ABADI, 2006). El aula-taller se divide en tres momentos: actividad inicial, síntesis informativa o desarrollo del marco teórico, y actividades de afianzamiento, integración y extensión. Los saberes previos de los participantes son recuperados por el educador y en algunos casos, revalorizados, y en ellos se hace el anclaje de nuevos saberes generados en esta nueva instancia de aprendizaje. Estas charlas fueron ofrecidas en las localidades de Miramar y Villa de Transito durante los meses de Marzo y Junio de 2012.

\section{Proyecto audiovisual}

Se trabajó sobre un proyecto documental titulado Lo tuyo, lo mío, lo nuestro... ¡Arqueología Pública, al Rescate!, con el doble objetivo de dar a conocer un nuevo campo de estudio de las Ciencias Antropológicas como es la Arqueología Pública en la Argentina, puntualmente tomando como caso nuestra experiencia de trabajo como Programa de Extensión.

A partir de indagar sobre el lugar que ocupa hoy en nuestra sociedad el patrimonio arqueológico, y su responsabilidad social y política, se analiza cómo se producen los procesos de patrimonialización. En este documental se plantea la necesidad de involucrar a la comunidad en las tareas de gestión, difusión y comunicación del patrimonio. El proyecto está compuesto por 4 capítulos que busca problematizar acerca de un tema muy caro a los cordobeses como es la presencia indígena, pasada y presente, buscando darle evidencias materiales y sustento teórico para mostrar su profundidad histórica y su diversidad en el modo de vida. 


\section{Algunas consideraciones}

Como hemos tratado de mostrar, nuestro trabajo como académicos de un Museo de Antropología interesados por la recuperación, estudios y puesta en valor de los patrimonios arqueológicos de la región en conjunto con las comunidades locales y las comunidades originarias, ha ido cambiando en sintonía con las nuevas miradas que ha tenido la sociedad en torno al pasado indígena de la región. La mirada retrospectiva elegida por nosotros para dar cuenta de la historia del programa permitió reflexionar y dar cuenta de los procesos de etnicidad iniciados recientemente en nuestra Provincia, el replanteo del rol del arqueólogo en su vínculo con la comunidad en torno al patrimonio, y los procesos de revalorización del patrimonio arqueológico por parte de la sociedad, entre otros temas. Hasta hace muy poco los pueblos originarios no se reconocían, ni demandaban participar en las decisiones sobre los bienes arqueológicos como lo hacen en este momento. Nosotros tenemos la relación con los pueblos originarios en el mismo territorio. Esta nueva realidad demanda una mirada reflexiva en la comunidad académica acerca de nuestro trabajo, y pensar la generación de metodologías de trabajo conjunta con los pueblos originarios y las comunidades locales.

Consideramos que nuestro programa de Arqueología Pública comparte con otros proyectos arqueológicos ciertos objetivos y miradas acerca de la disciplina y el rol social del arqueólogo. Seguramente, el trabajar en conjunto con aquellas comunidades que manifiesten preocupación por la protección del patrimonio arqueológico, así como acercar los saberes generados a partir de la investigación realizada sobre sitios y restos arqueológicos en riesgo de destrucción, pueden ser aspectos en común con otros proyectos similares. Sin embargo, hacer arqueología publica en Córdoba, puntualmente de la forma en la que hemos trabajado como equipo en este programa, tiene ciertas particularidades que pueden ser señaladas. En primer lugar, por estar inserto en un museo universitario de alta visibilidad y presencia en la sociedad cordobesa, nuestro programa pudo articular tanto las demandas en torno a la protección del patrimonio como la investigación de dichas colecciones. Además, este museo forma parte de una Facultad dedicada al estudio de las ciencias humanas y sociales, no naturales, como en el caso de otros museos universitarios de la Argentina. La formación de grado de la mayoría de los miembros del equipo proviene de la Historia con especialidad en Arqueología-, Biología, Geografía, y de postgrado en Antropología.

Otra particularidad está dada por las demandas en sí mismas: en su mayoría, se solicitó nuestra intervención en sitios arqueológicos definidos principalmente por la aparición de restos óseos humanos. Esta particularidad permitió que nuestro equipo se especializara en el análisis bioarqueológico de los restos, dando origen a una serie de proyectos de investigación y tesis de grado y postgrado que han abierto una nueva línea de indagación en ese aspecto de los estudios arqueológicos. 


\section{Bibliografía}

ABADI, Samuel. "Aplicaciones de metodología en el aula taller". XIV Jornadas de Reflexión Académica en Diseño y Comunicación. Experimentación, innovación, creación. Aportes a la enseñanza del Diseño y la Comunicación. Buenos Aires. Año VII, Vol. 7, 2006.

ACHINO, Lucia, DE CARLI, Cristina, ZABALA, Mariela, FABRA, Mariana. "Procesos de activación y valoración del patrimonio arqueológico a través de la Cartografía Social. Los casos de San Carlos Minas y Villa de Tránsito (Córdoba, Argentina)". Enviado a Revista EXT, Universidad Nacional de Córdoba. Ms en evaluación.

ALMANSA SANCHEZ, Jaime. "Arqueología para todos los públicos. Hacia una definición de la Arqueología Pública "a la española". ArqueoWeb. Revista de Arqueología en Internet, 13: p.87-107. 2011

CASTRO, Alicia; ZUBIMENDI, Miguel Angel; GRASSI, Luciano; AMBRUSTOLO, Pablo; MAZZITELLI, Lucia. Sitio arqueológico carsa (puerto deseado, Patagonia argentina): reflexiones sobre la práctica de una Arqueología Social y Pública. Revista Arqueologia Pública, p.7-21. 2007.

CONFORTI, María Eugenia. "Educación no formal y patrimonio arqueológico. Su articulación y conceptualización". Intersecciones antropol. (online). col 11, n¹1, p. 103-114. 2010.

CAPITANELli, Ricardo. "Clima". In: B. Vázquez, R.A. Miatello y M.E. Roqué (eds), Geografía física de la Provincia de Córdoba, Buenos Aires: J Ed. Boldt, p. 47-139. 1979.

ENDERE, María. Arqueología y legislación en Argentina. Cómo proteger el patrimonio arqueológico. Incuapa, Olavarria. 2000.

FABRA, Mariana. El poblamiento prehispánico de Córdoba: una interpretación a partir de evidencias bioantropológicas. Facultad de Filosofía y Humanidades, Universidad Nacional de Córdoba. ISBN: 978-950-33-0610-9. 1re. Edición, 232 páginas. Con referato externo. 2009

FABRA, Mariana, CASUSCELLI, Analía, GALIMBERTI, Soledad y URIBE, Alfonso, "Arqueología de Rescate: Su práctica y significación social en Córdoba". Actas XIII Congreso Nacional de Arqueología Argentina, Tomo IV, p.367-370. 2005.

FABRA, Mariana, SALEGA, Soledad, GONZALEZ, Claudina, SMEDING, Risha, PAUTASSI, Eduardo. "Arqueología de rescate en la costa sur de la Laguna Mar Chiquita: sitio arqueológico El Diquecito". Memorias del Pueblo: Revista del Museo Histórico Municipal La Para. 8 (8): p.37-46, Editorial Graphycor, ISSN: 1666-8839. 2008a.

FABRA, Mariana, ZABALA, Mariela E., ROURA GALTES, Isabel. "Reconocer, recuperar, proteger, valorar: practicas de Arqueología Publica en Córdoba". Arqueología y Educación: perspectivas contemporáneas, Ana Maria Rocchietti y Verónica Pernicone (compiladoras). Editorial Tercero en discordia, 218 páginas, p.117-132. ISBN 978-98724082-2-0. Tirada 200 ejemplares. 2008b.

FABRA, Mariana, GONZALEZ, Claudina, y SALEGA Soledad. "Modos de vida e historia biológica de poblaciones de las Sierra y Llanuras de Córdoba (Argentina): 
aproximaciones desde el registro bioarqueológico". Revista Argentina de Antropología Biológica. 2012. En prensa.

FABRA, Mariana y DEMARCHI Darío. Variabilidad craneofacial en poblaciones del sector austral de las Sierras Pampeanas: aportes desde la morfometría geométrica. Revista Relaciones de la Sociedad Argentina de Antropología, 34: p.1-24. ISSN 03252221. 2009

FUNARI, Pedro Paulo A. A Arqueologia pública na América Latina e seu contexto mundial. In: Fronteiras - Revista de História, Campo Grande, UFMS/PPG em História, vol. 6, n 11: p.87-96. 2002a.

FUNARI, Pedro Paulo A. Arqueología latinoamericana y su contexto histórico: la Arqueología pública y las tareas del quehacer arqueológico. Libro de sesiones y resúmenes III Reunión Internacional de Teoría Arqueológica en América del Sur, Colômbia. 2002b.

FUNARI, Pedro Paulo A.; ROBRAHN-GONZÁLEZ, Erica. Ethics, capitalism and public archaeology in Brazil. In: HAMILAKIS, Y.; DUKE, P. (eds.) Archaeology and Capitalism. From ethics to politics. Walnut Creek: Left Coast Press, p.137-150. 2007.

FUNARI, Pedro Paulo y ROBRAHN-GONZÁLEZ, Erica. Editorial. Revista Arqueologia Pública. São Paulo, n¹: 3. 2006.

GNECCO, Cristobal. Caminos a la arqueología pública. Libro de sesiones y resúmenes IV Reunión Internacional de Teoría Arqueológica en América del Sur, Inter-Congreso del WAC, p. 59. Catamarca: Argentina, 2007.

GARCÍA A.; DEMARCHI, D. Incidence and Distribution of Native American mtDNA Haplogroups in Central Argentina. Human Biology, 81(1): p.59-69. 2009.

LAGUENS, Andrés y BONNIN, Mirta. Sociedades indígenas de las Sierras Centrales. Arqueología de Córdoba y San Luis. Universidad Nacional de Córdoba. 2010.

PACHECO, Marcela. Reflexiones en torno a la construcción del espacio de la extensión universitaria hoy, 2008. Inédito.

SERRANO, Antonio. Los comechingones. Serie Aborígenes argentinos, Vol.I, Instituto de Arqueología, Lingüística y Folklore, Universidad Nacional de Córdoba. 1945.

TOGNETTI, Luis. "La introducción de la investigación científica en Córdoba a fines del siglo XIX: la Academia Nacional de Ciencias y la Facultad de Ciencias FísicoMatemáticas (1868-1878)". La Ciencia en la Argentina entre siglos. Textos, contextos e instituciones. Cuadernos Argentinos Manantial. p.345-365. 2000.

URIBE, Alfonso y OCHOA, Soledad. "Representaciones rupestres en el noroeste de Córdoba, Argentina. Valoración patrimonial de la Localidad arqueológica de La Playa". Arqueoweb. Revista sobre Arqueología en Internet, 10. 2008.

ZABALA, Mariela. Las verdades etnológicas de Monseñor Pablo Cabrera. Una etnografía de archivos en la ciudad de Córdoba. Tesis de Maestría. Inédita. 2010a.

ZABALA, Mariela, FABRA, Mariana, AICHINO, Lucia, DE CARLI, Cristina. "Educación patrimonial y derechos culturales: el aporte del patrimonio arqueológico en la construcción de identidades locales en el NE de la provincia de Córdoba". Revista 
$E+E$, Estudios de Extensión en Humanidades, Facultad de Filosofía y Humanidades, Universidad Nacional de Córdoba, Argentina. 2012. En prensa, volumen 4.

ZABALA, Mariela, MARTINI, Yoli y GARCÍA CONDE, Pilar. Patrimonio integral en tensión: comunidad local- comunidad académica. Revista E+E. Estudios de Extensión en Humanidades, Año 2. p.112-122. 2010b.

ZABALA, Mariela y ROURA GALTES, Isabel. Reflexiones teóricas sobre patrimonio, educación y museos. Revista de Teoría y Didáctica de las Ciencias Sociales. MéridaVenezuela. Enero-Diciembre. n 11. p.233-261. 2006.

ZABALA, Mariela y ROURA GALTES, Isabel. "La investigación arqueológica en relación con la comunidad. Reflexiones acerca de una experiencia de Educación Patrimonial en el Departamento Minas". Arqueoweb. Revista sobre Arqueología en Internet, n¹0. 2008

ZABALA, Mariela, ROURA GALTES, Isabel y ASSANDRI, Susana. "Extensión universitaria y TIC. Reflexiones de la práctica docente en la problemática de la Educación Patrimonial". RIED - Revista Iberoamericana de Educación a Distancia Volumen 13, n 1. p.111-127. 2010c. 